\title{
Poliomielite: várias histórias da doença e de seus efeitos tardios
}

Poliomyelitis: several stories of the disease and its after effects

\author{
Lina Faria \\ Coordenadora do Curso de Fisioterapia/Universidade Federal de Juiz de Fora. \\ lina.faria@uff.edu.br
}

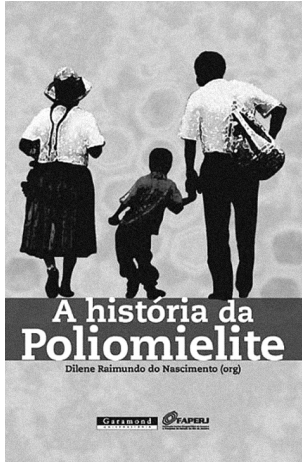

NASCIMENTO, Dilene

Raimundo do et al. (Org.). A história da poliomielite. Rio de Janeiro:

Garamond. 2010. 416p.
Proteger uma criança da pólio é tão fácil quanto protegê-la da chuva: trata-se de colocá-la sob o equivalente médico de um guarda-chuva. Kofi Annan (Salgado, 2003).

Ao discutir a luta contra a poliomielite no Brasil, a obra A história da poliomielite, organizada pela pesquisadora da Fiocruz Dilene Raimundo do Nascimento, traz alguns capítulos sobre o enfrentamento da doença no Peru (Marcos Cueto et al.), Portugal (Inês Santos), Espanha (Juan Rodríguez Sánchez) e Paquistão (José Verani). No Brasil (Dilene Nascimento, André Campos, Ângela Pôrto) e nos outros países, o livro aborda, entre vários temas, as questões correlatas de "controle e erradicação" da pólio, a evolução das campanhas e dos resultados obtidos, os distintos contextos sanitários e a eficácia ou o fracasso das políticas sanitárias postas em prática em cada país.

Dividido em quatro partes, o livro constrói uma narrativa histórica e analítica do ambiente da saúde nacional e internacional do pós-Segunda Guerra Mundial. Chama a atenção para a formulação e execução de políticas de saúde que foram postas em ação e que tinham como meta a erradicação da doença - as estratégias nacionais de combate; o desenvolvimento de técnicas laboratoriais para diagnóstico; as campanhas de vacinação, que buscavam mudar o quadro da poliomielite no Brasil e no mundo.

Os debates tiveram início nas primeiras décadas do século XX, quando a enfermidade passou a se manifestar sob forma epidêmica em várias partes do mundo. A epidemia assolou tanto países ricos, como os EUA, a Inglaterra e a Suécia, quanto países periféricos, como a Índia, a Somália, a República Democrática do Congo, o Paquistão e o Sudão. Cada vez mais incontrolável e destrutiva, fazia vítimas fatais e deixava milhares de crianças e adultos paralisados.

Médicos e autoridades sanitárias desconheciam por que caminhos a pólio se disseminava: os caminhos eram difíceis de ser previstos; a doença, difícil de ser evitada e de ser tratada de forma eficiente. A partir de 1950 surgem novas tecnologias de controle e erradicação da doença, 
além da descoberta das vacinas Salk (em 1955) e Sabin (em 1961). A obra sugere que o trabalho desses cientistas e de seus companheiros, bem como dos que os antecederam nas primeiras pesquisas com o vírus, conduzidas a partir do início do século XX, foram fundamentais na luta pela erradicação, em várias partes do mundo.

Desde os primeiros estudos a seu respeito, a poliomielite constituiu um ponto de interrogação para as autoridades sanitárias em todo o mundo. Interessante é o depoimento do médico João Risi, segundo o qual, quando as condições sociais são precárias, a criança mais cedo exposta ao vírus dificilmente assume a forma paralítica da doença. O contato precoce garante maior possibilidade de desenvolvê-la em sua forma benigna, ficando menos suscetível às manifestações neurológicas da doença.

Diante das incertezas que a pólio impunha sobre o conhecimento médico, da diversidade de modelos e de terapias pouco eficazes, era frequente a atitude de "negação", pelas autoridades médicas e sanitárias de alguns países, o Brasil entre eles, da existência de epidemias de poliomielite. Os capítulos assinados por Sánchez e Campos trazem, a propósito, noticiários e manchetes em jornais e revistas que indicam a desinformação, as "responsabilidades não assumidas", a insistência sobre a "não existência" de epidemia de pólio.

\section{A poliomielite no Brasil}

Temas como os mencionados nos parágrafos anteriores são a primeira pista, para o leitor, da relevância da obra. A apresentação cuidadosa, pela organizadora, traça o plano geral do livro. A história da poliomielite, em sua primeira parte, é dividida em cinco capítulos sobre a trajetória da doença no Brasil, que focalizam o desenvolvimento e a legitimação das políticas públicas de controle. Os autores discutem os modelos científicos explicativos da pólio, o debate e as controvérsias no país, os surtos epidêmicos em vários estados, as vantagens e desvantagens das vacinas, as campanhas de vacinação e os dilemas dos cientistas brasileiros em relação à descrição clínica da doença.

O trabalho de André Campos, que abre o volume, investiga as primeiras epidemias que ocorreram no Rio de Janeiro, em 1911, e em São Paulo, em 1917; apresentam-se os diferentes modelos científicos explicativos da doença, em especial, as discordâncias entre Fernandes Figueira e Francisco de Salles Gomes Júnior no tocante à descrição clínica e ao tratamento mais adequado. Nas décadas de 1930 e 1940 foram registrados surtos na capital federal e nos estados de Minas Gerais, Espírito Santo, Rio Grande do Sul e Santa Catarina; no Nordeste e Norte, foram atingidos a Bahia, Sergipe, Maranhão, Piauí e Amazonas. Neste período, a doença não havia recebido no Brasil a atenção que despertava em outros países, como nos EUA, Inglaterra e Suécia, com centenas de vítimas de pólio e de paralisia.

Chamava atenção a incapacidade da medicina de dar uma resposta eficaz ao problema e à forte influência do modelo de contágio direto para a pólio, dominante durante os anos de 1930 e 1940. De acordo com esse modelo, diz o autor, a pólio era transmitida por via respiratória - secreções nasais e bucais. Seu modo de transmissão era típico, portanto, das doenças respiratórias - o vírus penetrava pelas vias aéreas superiores e viajava diretamente para o sistema nervoso central, provocando uma paralisia flácida aguda em membros inferiores, com perda parcial ou total da capacidade de contração do músculo. Contudo, os avanços da 
virologia e o surgimento do microscópio eletrônico possibilitaram uma compreensão mais ampla da doença. No final dos anos de 1940 a pólio passou a ser vista não mais como doença neurológica e sim entérica, isto é, o vírus se multiplicava no trato gastrointestinal, e a infecção podia ser transmitida pela via fecal-oral.

O capítulo 2, que traz uma interessante discussão histórica sobre o desenvolvimento de vacinas, por Eduardo Ponce Maranhão, não focaliza o cenário brasileiro, apesar de constar da Parte 1 sobre o Brasil. Neste capítulo, o autor indica que a eficácia dos tratamentos dependia dos avanços científicos, que levariam à descoberta das vacinas Salk e Sabin, e dos ensaios e estudos de campo conduzidos em vários países em busca de medidas apropriadas para o isolamento dos vírus. Maranhão discute um capítulo fundamental da história da pólio no mundo: as pesquisas com cultura de tecido. Em 1949, cientistas dos EUA descobrem uma nova técnica para cultivar o vírus em tecidos mais simples (embriões de galinha) e não apenas em macacos. Em 1953 Jonas Salk anuncia as primeiras experiências de sua vacina em humanos com resultados positivos, e no ano seguinte a vacina é testada em grande escala. Em 1957 realiza-se o primeiro ensaio de campo com a vacina Sabin oral, em Cingapura. A vacina oral contra a pólio foi obtida a partir de um vírus vivo, diferentemente da vacina Salk, baseada em uma cepa morta do vírus. No Brasil, a vacinação pela vacina Salk é introduzida em 1955, em São Paulo e, no ano seguinte, no Rio de Janeiro. Em 1953, a epidemia atinge fortemente a capital federal.

É importante ressaltar que as ações de combate, iniciadas nos finais dos anos de 1950 no Brasil, se intensificaram nos anos de 1970 com o surgimento do Plano Nacional de Controle da Poliomielite estabelecido pelo Ministério da Saúde. Contudo, foi na década de 1980 que houve uma mudança de estratégia, de "controle", para uma política de "erradicação" da poliomielite. Os anos 1980 marcam o processo de abertura política e da luta pela implantação de mudanças sociais. Na área da saúde, discute-se um novo modelo de atenção, mais abrangente, com a participação da comunidade em todos os níveis de governo, melhorando o acesso das populações menos favorecidas à saúde. A saúde passa a ser vista como uma questão social, o controle da poliomielite a inserir-se no movimento pela reforma sanitária. Alguns desses marcos históricos foram discutidos por Dilene Nascimento. A autora analisa o processo político na área da saúde, com base em seis marcos fundamentais: a introdução da vacina Sabin em 1961; o diagnóstico laboratorial do poliovírus, em 1961; o Plano Nacional de Controle da Poliomielite, em 1971; a implantação do Sistema Nacional de Vigilância Epidemiológica, em 1975; os Dias Nacionais de Vacinação, em 1980, e a estratégia de erradicação da doença a partir de 1985.

A pólio produz repercussões na construção da identidade individual dos atingidos que precisam enfrentar as sequelas, sobretudo o estigma, ao longo de suas vidas. O trabalho de Ângela Pôrto reúne três depoimentos de mulheres com sequelas motoras graves, que contraíram a doença nos anos de 1950. O recurso às fontes orais permite recuperar vivências e memórias da doença, dando voz aos enfermos. Crescem o interesse pelos aspectos do cotidiano do indivíduo ou de grupos específicos e o conhecimento das experiências individuais, das estratégias de enfrentamento da doença e de suas sequelas. Busca-se pensar a doença, ou o doente, dentro do seu contexto sociocultural; qual a percepção dos indivíduos sobre sua saúde, considerada nos valores dentro dos quais vive? Quais são os limites impostos pela 
doença e os efeitos na sua vida diária? Os depoimentos recuperam a memória e reconstroem as identidades dessas pessoas, diz a autora; a doença não pode mais ser discutida como um evento médico, mas sim como um acontecimento social.

O último capítulo da primeira parte do livro, também organizado por Ângela Pôrto, reúne algumas imagens das campanhas do Ministério da Saúde, especialmente os Dias Nacionais de Vacinação, instituídos em 1980. Esse material, coletado pela autora, mostra mudanças, ao longo dos anos, no tipo de mensagem que se queria fixar em relação à doença e ao portador de deficiência.

\section{A poliomielite fora do Brasil}

A segunda parte do livro, dividida em quatro capítulos, reúne artigos sobre o controle e erradicação da poliomielite em outros países. Intitulada "A poliomielite na América Latina, Europa e Ásia", talvez venha a sugerir ao leitor um cenário mais amplo do que aquele focalizado pelos capítulos, restritos na verdade a poucos países. Isso não impede que se note a relevância dos estudos de caso expostos. Na apresentação do livro, há menção à "novidade incomum" de a obra vir a "possibilitar análises histórico-comparadas de outras experiências nacionais". Aqui há controvérsia. Os casos nacionais, trabalhados sem preocupação metodológica com a análise comparativa, dificilmente permitem ao leitor estabelecer contrastes ou semelhanças. Talvez a ausência de tal esforço comparativo na própria apresentação feita por Nascimento revele a dificuldade de se encontrar no texto a "novidade incomum". O único esforço comparativo digno de nota está no texto de Nascimento e cola-boradores sobre o processo de erradicação da pólio no Brasil e no Peru, nos anos de 1980, com ênfase nos contextos políticos, sociais e sanitários. Os autores indicam que, diferentemente do Brasil, onde o movimento social pela reforma sanitária, inaugurado nos anos de 1970, vinha reivindicando a participação da comunidade (ainda que com imensas dificuldades e limitações de toda sorte, acrescentamos), no Peru não se assistia a iniciativas de estímulo à participação ou envolvimento da população.

Inês Guerra, em estudo sobre a experiência portuguesa, mostra como a doença foi negligenciada durante várias décadas pelas autoridades sanitárias e políticas. Segundo a autora, o elevado número de mortes e de crianças e jovens incapacitados pela doença não foi suficiente para que a poliomielite fosse considerada oficialmente um problema de saúde pública. Contudo, o trabalho discute uma iniciativa importante, representada pelo Refúgio da Paralisia Infantil, fundado em 1926, pelo médico neurologista Henrique Gomes D'Araújo, destinado à assistência e ao tratamento gratuito de crianças pobres da cidade do Porto, na época, uma das cidades mais insalubres de Portugal. Embora dependente de contribuições externas para manter tratamentos gratuitos, o Refúgio contava com uma estrutura na qual funcionava, além do Serviço de Fisioterapia, a Hidroterapia, a Recuperação Funcional e a Cirurgia Ortopédica.

Juan Sánchez discute as "responsabilidades não assumidas" pelo Estado espanhol em relação à erradicação da poliomielite no país, nos anos de 1950 e 1960. Lembra que no pósguerra tanto Portugal quanto a Espanha eram países com governos ditatoriais e de tradição confessional católica, "dois elementos determinantes da sua resistência a conceber saúde e assistência em termos de direito" (p.195). Essas características se concretizaram em campanhas 
de vacinação tardias, pouco difundidas e sem a eficácia esperada. Além disso, lembra o autor, a vacina não era oferecida gratuitamente à população, logo não podia tornar-se obrigatória. Minimizava-se a importância do problema, criavam-se dúvidas sobre a eficácia da vacina e negava-se a gravidade e existência de surtos epidemiológicos - para o Estado a vacina "não era necessária". "Repressão e autocensura se aliaram para minimizar o problema sanitário" (p.206). Mas, diferentemente de outras doenças como a cólera ou a gripe espanhola, a poliomielite tinha como consequência sequelas paralíticas visíveis para a população, que desafiavam qualquer ocultação ou negação de seus efeitos.

O Paquistão é também um caso de ações tardias de combate à poliomielite. Lá, todas as atividades de erradicação tiveram o apoio financeiro de organizações internacionais, como a Organização Mundial da Saúde e o Fundo das Nações Unidas para a Infância e não governamentais, como o Rotary Internacional. Nos anos de 1980 tiveram início as primeiras campanhas, a partir da criação do Programa Ampliado de Imunização - BCG, pólio oral, DTP e antissarampo. Os postos e centros de saúde desempenharam papel de destaque na oferta de vacina de forma rotineira. Em 1994 foi organizada a primeira Campanha Nacional de Vacinação Antipólio. Segundo Verani, entre os anos de 1994 e 2000, durante o governo talibã, as campanhas não conseguiram atingir a cobertura esperada pelas autoridades sanitárias, em função do caráter localizado dos programas. Além disso, os fluxos de refugiados, as fronteiras tensas entre Afeganistão, Irã, Índia e China e a própria cultura islâmica fundamentalista, dificultando a acesso às mães pelas equipes de saúde pública, constituíram barreiras para a erradicação da doença.

\section{Os efeitos tardios da poliomielite: "uma nova doença velha"}

A terceira parte do livro, dividida em dois capítulos, discute a síndrome pós-poliomielite (SPP), um dos efeitos tardios da poliomielite, que compreende um conjunto específico de novos problemas de saúde originados pelo vírus da pólio e que vem atingindo pessoas acometidas pela doença décadas atrás. No final dos anos de 1970, os sobreviventes começaram a sofrer novos problemas, tais como fadiga, dor e fraqueza, resultando na diminuição da capacidade funcional e/ou no surgimento de novas incapacidades. Em função do aumento de números de casos da SPP no Brasil e do escasso conhecimento, pela comunidade médica, acerca dos efeitos tardios da pólio, a Associação Brasileira de Síndrome Pós-poliomielite (Abraspp) luta para que se estabeleçam políticas públicas que beneficiem aqueles com sequelas da pós-pólio.

O capítulo dez, sobre a conceituação e aspectos clínicos da SPP, contou com a participação de profissionais do Setor de Doenças Neuromusculares da Universidade Federal de São Paulo (Unifesp)/Escola Paulista de Medicina (EPM). É importante destacar que a primeira linha de pesquisas sobre as características clínicas da SPP, teve início em 2003, sob a coordenação do fisioterapeuta Abrahão Augusto Juviniano Quadros, no ambulatório de SPP do Setor de Doenças Neuromusculares da Unifesp. O capítulo discute de modo cuidadoso a SPP, uma neuropatia motora degenerativa, de etiologia multifatorial e de progressão lenta, que se manifesta em indivíduos portadores da poliomielite anterior aguda. Ocorre em indivíduos que tiveram pólio há pelo menos 15 anos, com ou sem sequela paralítica, e se caracteriza por nova fraqueza muscular progressiva, fadiga, dores musculares e/ou nas articulações, resultando numa 
diminuição da capacidade funcional e/ou surgimento de novas incapacidades. Um critério importante que fundamenta o diagnóstico é a confirmação da poliomielite anterior aguda com evidência de perda neuronal, por meio de exame neurológico e da eletroneuromiografia.

No capítulo seguinte, Solane Carvalho de Lima, diretora da Abraspp, fala dos desafios dessa "nova doença velha" para os profissionais de saúde e para os sobreviventes da pólio, além da importância de criação de uma instituição que represente os portadores da síndrome. De acordo com essa autora, a primeira descrição clínica da doença no Brasil foi publicada na Revista de Neurociências, em 2002. No ano seguinte, teve início o atendimento de sobreviventes da pólio, com sintomas da SPP, no Setor de Investigação em Doenças Neuromusculares da Unifesp/EPM. Além da contribuição para as primeiras pesquisas sobre a SPP e seus efeitos no Brasil, o grupo da EPM participou também da criação, em 2004, da Abraspp - espaço de debates e difusão de informações sobre a SPP - que busca facilitar o acesso de pessoas com SPP ao tratamento.

\section{Os depoimentos}

A última parte do livro apresenta os depoimentos dos especialistas João Baptista Risi Júnior e Ciro de Quadros, material que compõe o acervo do projeto "A história da poliomielite e de sua erradicação no Brasil" - acervo de depoimentos orais da Casa de Oswaldo Cruz (Fiocruz). Esses dois médicos estiveram na direção dos processos de controle e erradicação da poliomielite no Brasil e na coordenação da erradicação nas Américas. João Risi narra passagens importantes no cenário brasileiro, enquanto Ciro de Quadros discorre sobre o tema em âmbito internacional. As entrevistas tiveram como temática principal a história da poliomielite, mas foram abordados outros assuntos importantes para o entendimento da trajetória da enfermidade no Brasil e nas Américas.

Os leitores da obra A história da poliomielite muito se beneficiarão da consulta a uma obra já clássica na literatura mundial, O fim da pólio: a campanha mundial para a erradicação da doença, organizada pelo fotógrafo Sebastião Salgado (2003), com textos traduzidos dos originais em inglês de vários especialistas e estudiosos internacionais, entre os quais os médicos epidemiologistas Katja Schemionek e Chris Zimmerman e a escritora Carole Naggar, a quem o doutor Ciro de Quadros também concedeu uma entrevista, em dezembro de 2002, reproduzida na íntegra. Imagens belíssimas e impactantes, fixadas por Sebastião Salgado, acompanham o registro das campanhas de vacinação em países estrangeiros não abordados na obra organizada por Nascimento (alem do Paquistão, incluem-se relatos sobre as campanhas na Índia, na Somália, no Sudão e na República Democrática do Congo). Os autores da obra brasileira poderiam, talvez, ter buscado um diálogo com os textos do livro organizado e ilustrado por Salgado. Isso por certo não impede que a presente obra publicada pela Garamond, com apoio da Faperj, seja uma contribuição extremamente relevante à literatura. Por certo haverá novas edições da importante obra; quando isto se der, será oportuna a montagem de um cuidadoso índice onomástico e de assuntos, imprescindível em um texto de consulta obrigatória como A história da poliomielite. 


\section{REFERÊNCIAS}

SALGADO, Sebastião.

O fim da pólio: a campanha mundial para a erradicação da doença. Fotos de Sebastião Salgado; prefácio de Kofi A. Annan. São Paulo: Companhia das Letras. 2003. 